\title{
Sibling Interaction and Symbolic Capital: Toward a Theory of Political Micro-economy
}

\section{Introduction}

\author{
Chad Nilep
}

This paper describes the behavior of four individual members of a family as expressions both of identity and of symbolic power. The family observed, mother Mami, teenaged daughters Otoe, 18, and Yumi, 14, and ten-year-old son Ryu, are Japanese-Americans living in Colorado. Mami is a first-generation American immigrant from Japan; her children are US-born Japanese Americans. The behavior of primary interest is the choice of language - either Japanese or English - which each family member uses in particular situations. I will argue that these four individuals relate to one another based on hierarchical rank, using both language choice and interactional strategies to achieve positions within the family hierarchy. Moreover, there is evidence for multiple hierarchies or social arrangements, based on multiple roles or identities of each individual and on stances relative to a variety of social categories. Individuals must thus negotiate their relative status (and solidarity) based on the relevant hierarchy for a particular activity or frame.

In addition, I will argue that a position within a hierarchy is a social asset, related to social power. That is, getting and holding a position within a hierarchy both requires and bestows power and privilege. The hierarchical structure of the family distributes power unequally among family members. Thus, the subject positions of individual actors both emerge from this structure and reproduce it.' The confluence of these factors echoes, at a local level, the social structures described by Ortner's (1989) expanded practice theory, as well as symbolic and linguistic approaches to political economy ${ }^{2}$ (Friedrich, 1989; Gal, 1989, inter alia).

Perhaps the primary statement of language and political economy originates with sociologist Pierre Bourdieu. His Ce que parler veut dire (Bourdieu, 1982) was originally delivered in 1977. By the time the English translation, Language and Symbolic Power, was published in 1991, Bourdieu's concepts of symbolic domination and the linguistic marketplace were already being applied by American linguistic anthropologists (e.g. Friedrich, 1989; Irvine, 1989). Although some linguists have approached Bourdieu's notions of symbolic domination and the linguistic market as metaphors, I argue that language and political economy is better thought of as a metonym - reference to an institution by way of properties of the institution. The institution here is unequal distribution of power, control, and autonomy, as well as capital; the property by which it is referenced is the exchange of goods, the market.

What approaches to political economy in the fields of linguistic and cultural anthropology have in common with economics as a field is an interest in unintended

\footnotetext{
${ }^{1}$ The observation that societal institutions and individual subjects are reciprocally constituted has been made not only in practice theory (Bourdieu, 1977b) and other social theories cited herein, but also in sociocultural anthropology (Geertz, 1973), ethnomethodology (Heritage, 1984), speech act theory (Austin, 1962; Mey, 2006), inter alia.

${ }^{2}$ Throughout this paper, I use the term "political economy" to refer to approaches in anthropology and related social sciences. I refer to the field of study which Adam Smith ([1776] 1993) named "political economy" with the contemporary American label, "economics."
} 
consequences. As the individual capitalist is apt to maintain the wealth of the state as though guided by an invisible hand (Smith, 1993), so the individual speaker/hearer is liable to maintain the ideological structures of her/his culture or society regardless of her/his intent. Javanaud makes clear the unintended consequences of cultural practices in his (1987) review of Bourdieu's Ce que parler veut dire.

Bourdieu is not primarily dealing with conscious intentions. What governs groups of people (including philosophers) is not of a mechanical, cybernetical or system-theoretic nature. They act neither deterministically nor in [a] transparent teleological way. Decisions may appear free and yet are constrained. Our decisions are not normally the result of cynical calculations, even if such calculations can enter into them. Rather, our habitus implies a disposition to act conditioned by its acquisition and use on certain markets (Javanaud, 1987:810-11).

This work examines the construction and maintenance of identity by the display of acts and stances, including language behavior. According to Bucholtz and Hall (2004), language and identity is in many ways central to the study of linguistic anthropology. I seek here to relate notions of political economy with notions of personal or local identity. This study entails a concern for the production of individual subject positions, including the means by which identities are created, socialized, and reproduced.

I argue that older siblings serve to socialize younger ones into locally appropriate roles, while at the same time working to build and maintain their own roles. This identity work yields symbolic capital to the older sibling and recreates the market for its further exploitation by reproducing appropriate social hierarchies.

The notion of symbolic capital comes, of course, from studies of language and political economy. Such studies originate with Marxist scholars' turn toward symbolic anthropology and discourse analysis, as well as linguistic anthropologists' turn toward power and institutions (Gal, 1989). As such, studies of political economy often take as their analytic focus nation-states (e.g. Irvine, 1989), or major class or language divisions within a state (e.g. Bourdieu, 1977b; Woolard, 1989). However, the 'common sense' of the nation - if there is such a thing ${ }^{3}$ - must reside within the common senses of its members. The collective identity and collected practices that help constitute the nation are experienced at the individual level, by actors in face-to-face contact with other individuals (Suleiman, 2003).

Theories of social reproduction (Althusser, 1972) suggest that capitalist societies must reproduce properly socialized individuals in order to maintain themselves. According to the social reproduction model, individuals are taught appropriate class, gender, and other roles via participation in institutions such as the legal system and schools. This model of socialization has been criticized as overly deterministic, and dismissive of individual agency and practice. Later theories of practice and of political economy (Bourdieu, 1977a; 1977b) preserve a role for individual autonomy, but an autonomy that is limited by the potentials of social structures that are culturally

\footnotetext{
${ }^{3}$ Herzfeld (2001), for example, suggests that nationalism or 'national culture' conflates cultural boundaries with the borders of the state.
} 
reproduced. Nothing in this paper should be taken to suggest that any individual can radically reshape these social structures. However, where models of social or cultural reproduction see socializing influences primarily or exclusively in organs of the state or the capitalist economy, the theory suggested here sees these structures extending into more local, even individual levels. In turn, the socialization of members of society comes not only from participation in recognized institutions, but even from the often hierarchical organization of face-to-face conversation. As the data in this paper suggest, even interactions among siblings serve socialization into the norms of the linguistic marketplace.

The analyst may describe the relationship between the individual experience necessary for socialization and the collective experience of the linguistic market as a pattern of fractal recursivity (Irvine and Gal, 2000). In mathematics, a fractal is a rough geometric shape that is self-similar at different scales. In other words, smaller portions of the form resemble larger portions, as well as the form as a whole (at least approximately). This notion of fractal geometry is useful in social science ${ }^{4}$, where broad social norms are obeyed in the behavior of individuals, while individual patterns of behavior or thought can be seen to recur in larger institutions. Irvine and Gal identify fractal recursivity as one of the semiotic processes by which individuals construct ideological representations of group distinction. Perceptions of opposition at one level of analysis are projected onto other levels, recreating the ideology of distinction. For example, opinions about an individual are attributed to a group the individual belongs to.

Fractal recursivity is not only useful for describing the individual's ideology of distinction at various levels of analysis, but also for relating individual behavior to the structure of society. Sapir (1995) suggested that the difference between individual and society is largely a matter of the analyst's focus. Society is thus seen as the collected senses of individuals. Particular differences do not obliterate the self-similarity of the individual and the group; like a fractal, form is independent of scale. Thus, I assume that an extremely local analysis can be a valid starting point for the analysis of 'culture' or 'common sense' (Herzfeld, 2001). A microanalysis of the individual members of Mami's family should add to our understanding of symbolic domination, socialization, and practice at other, more macro-levels. This is not to say that the analysis of family interaction is the only or even the ideal site at which to study these notions. Indeed, the insensibility of a culture from the outside suggests that analysis must ultimately look more widely for the borders of common sense. However, I hope that this analysis might provide a preliminary step to mediate between the experience of face-to-face interaction and macro-historical processes and the exercise of institutional power (Gal, 1989:349$350)$.

\section{Results and Discussion}

What follows is a close reading of interactions between Mami and her family. Transcripts of audio recordings are included to illustrate the specific actions of each individual, and the way they reproduce and reflect social role. In addition to the linguistic data illustrated here, analyses are based on field notes made during participant observation of various

\footnotetext{
${ }^{4}$ Irvine and Gal (2000) trace the notion of fractals in anthropology as far back as Bateson (1936). For discussion of fractal geometry in economics, see Takayasu et al. (2000).
} 
Japanese American families in the Colorado Front Range. However, the primary focus is on code switching and language choice as a particularly visible site for the assessment of social role.

In the data that follow, Mami speaks Japanese to her children. Mami is a native speaker of Japanese, with some English proficiency. All three children are bilingual speakers $^{5}$ of English and Japanese. Within the home, Mami prefers to use Japanese as a means of heritage language maintenance (compare Langager, 2001; Cashman, 2001). She requires that her children speak Japanese at home, with the understanding that they will rely primarily on English outside the home. Although I gathered no data from outside the home, it seems safe to assume that little interaction outside the family takes place through the medium of Japanese. ${ }^{6}$ According to an analysis of the 2000 US census carried out by the Social Science Data Analysis Network (2002), approximately 85\% of Colorado residents are English monolinguals. In addition, approximately 11\% of Colorado residents speak Spanish, while fewer than two percent speak an "Asian language," which SSDAN defines as any non-Indo-European language spoken in Asia. Thus, the Japanese speaking population of the region may be assumed to be quite small.

\section{1. "It's a math problem"}

Since Mami speaks Japanese to her children, the language serves an indexical function (Silverstein, 1995). Mami's use of Japanese to enact behaviors such as teaching, directing action, and scolding builds a semiotic link between these acts and the language used to perform them, so that Japanese indexes social roles such as Teacher, Director, and Authority, as well as the broader role of Mother.

In Excerpt 1, Mami both indexes and achieves her role as Mother through appropriate actions, which Yumi ratifies in turn. This identity position should not be understood as a static property of the individual, but rather as a position that must be constantly achieved and ratified through interaction (Ochs, 1993; Lo, 1999; Bucholtz and Hall, 2004 inter alia). Yumi similarly achieves her identity as Daughter through locally appropriate behavior.

(1) Excerpt 1 "It's a math problem"

$1 \quad$ M: ni-juu kyu doru kyu juu

kyu sento desu

$2 \quad Y:$ ee?

$3(2.0)$

4 Y: ni doru ha?

5 M: ha? ni-hyaku go juu minutes de

$6 \quad \mathrm{Y}: \mathrm{nn}$

7 M: ni-juu kyu doru kyu-juu

8 kyu sento $\left({ }^{\circ} \operatorname{desu}{ }^{\circ}\right)$
It's twenty dollars and ninety-nine cents.

huh?

Two dollars?

huh? For two hundred and fifty minutes

yeah

twenty dollars and ninety-nine cents.

${ }^{5}$ These claims are made without the benefit of testing or serious inquiry into the nature of the children's linguistic competence. However, as the data show, each child is able to produce fluent discourse, both formally and pragmatically consistent with native-speaker competence in English as well as Japanese.

${ }^{6}$ One exception is the Japanese-medium supplementary school that Ryu attends on Saturdays. 


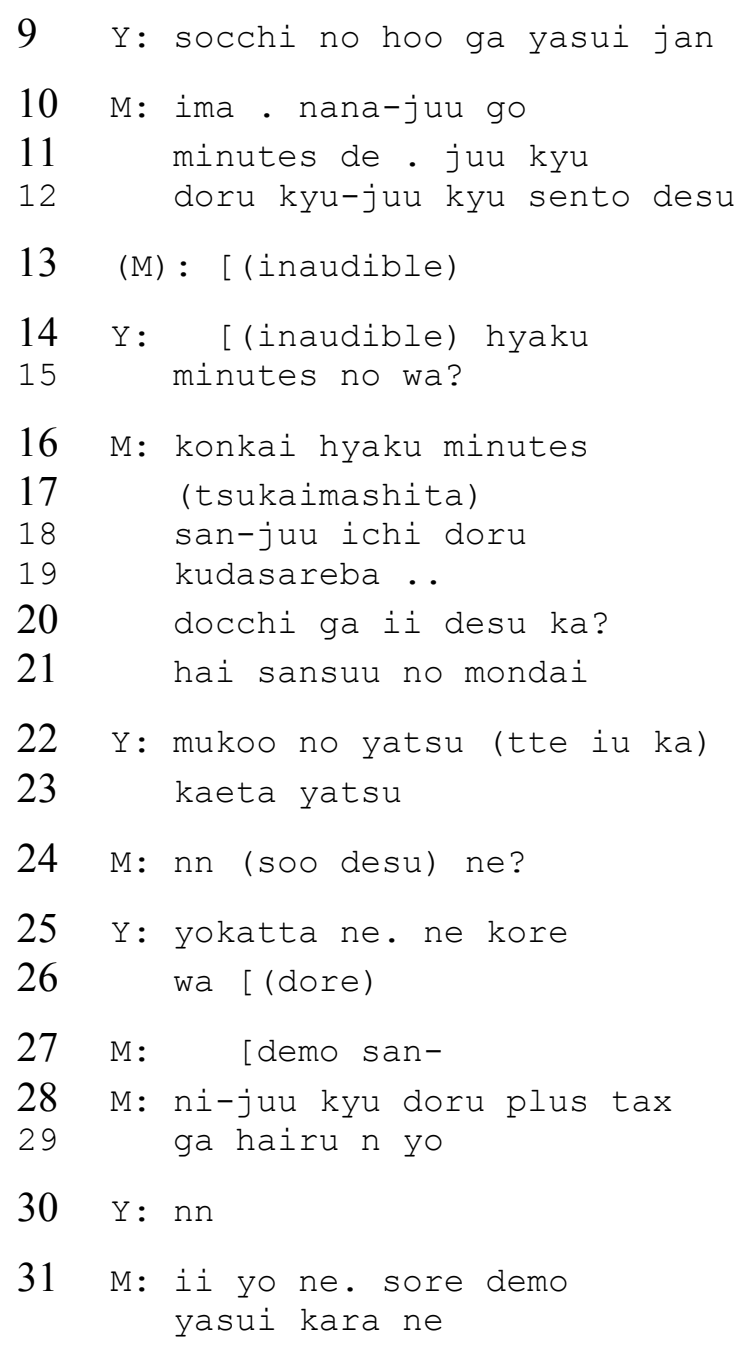

In Excerpt 1, Mami serves her position as Mother by enacting several stances, which make up the role. At the same time, Yumi enacts stances proper to her role as Daughter. Mami and Yumi are discussing the price of long-distance calling cards. Throughout the conversation, Mami possesses information, which she gives to Yumi. She repeatedly (lines 1, 5-7, 10-11, 16-19) gives Yumi specific information about the cost of various cards and their denomination in minutes. Then, at lines 20-21, Mami asks Yumi to decide which card is the best value, posing the question as an academic exercise. Docchi ga ii desu ka? Hai, sansuu no mondai. "Which is better? Right, it's a math problem." These acts position Mami as Teacher in this interaction. Yumi's responses, in turn, serve to ratify Mami's position. She evaluates Mami's information (line 9), asks for more information (lines 14-15), and generally allows Mami to maintain primary speakership (Jefferson, 1984). Notice how the women use questions to accomplish different roles within the interaction. Yumi's question Hyaku minutes no wa? "What about the one with a hundred minutes?" requests information that Mami possesses and Yumi wishes to know, namely, the price of the phone card. However, Mami's Docchi ga ii desu ka? "Which one is better?" directs Yumi to manipulate the information Mami has provided her. This is not purely a request for information, since Mami already possesses all of the 
relevant information and has just given it to Yumi. Instead, it is a directive, specifically marked as sansuu no mondai "an arithmetic problem."

By acting both as Teacher and as Director, offering information and directing Yumi to manipulate it, Mami enacts a position as Mother. Further, as the data show, Mother is a relatively more powerful role: she is able to direct Yumi's action (lines 2021) and to evaluate her solution (line 24). Furthermore, she is not obliged to respond to Yumi's questions or requests for clarification (lines 2-4 and 25-26).

\section{2 "Happy? Lucky?”}

Japanese and English are each associated with different social roles, an association built through a process of indexicalization. English is the dominant language of the broader society outside of this household. In the community at large, it is associated with powerful institutions of the state, education, and business. Within the household, however, Japanese is Mami's preferred language. Although she can speak English (for example, she speaks English to me), Japanese is her dominant language; she almost always uses it when speaking to her children. Thus, since Japanese is associated with a particular role within the family hierarchy, the language becomes an index of that role. Using another language facilitates stepping outside that role to enact other aspects of personal identity. In excerpt two, the use of English calls upon an alternate set of identities and relationships, an alternative identity market.

(2) Excerpt 2. "Lucky? Happy?"

$\begin{array}{ll}1 \text { Y: doo shiyoo ka na } & \text { What should I do? } \\ 2 \text { M: Otoe-neechan ni mo aji } & \text { Ask sister Otoe to taste a little bit. } \\ 3 \text { Chotto mite moratte } & \\ 4 \text { Y: (inaudible) } & (\text { ) } \\ 5 \text { M: [ha hm } & \text { ha hm } \\ 6 \text { O: [heh huh } & \text { heh huh } \\ 7 \text { Y: (inaudible) } & \text { ( ) } \\ 8 \text { M: lucky? happy? } & \text { Lucky? Happy? }\end{array}$

Notice that the English used here is limited to single words. Mami typically uses single words or short phrases when speaking to her children in English. Moreover, the words used appear somewhat ill suited. Mami and her daughters are preparing dinner; Yumi is making a salad dressing. Mami instructs Yumi to let Otoe taste the dressing, and asks Otoe for her opinion. While we might expect the dressing to be described as oishii "tasty," Mami uses English words that express a positive connotation - though they would not usually be expected when describing food.

As we have seen, Mami uses Japanese when instructing Yumi or giving her direct commands, enacting a role as Teacher or Director, consistent with her position as Mother in the family hierarchy. In the English-dominant community outside the household, however, the relatively more fluent Otoe and Yumi hold more social capital. At lines 2-3, Mami issues a directive to Yumi in Japanese without apparent regard for politeness or 
face. Both the linguistic medium and the lack of politeness markers show Mami's relatively higher status. In contrast, at line 8 Mami uses English words to elicit Otoe's opinion of the food offered; this change in language indexes a change in role. Mami is soliciting Otoe's assessment, and marks their changed roles and statuses by changing linguistic form. English is the language of prestige and power in the broader community, outside the family. In this interaction Mami's powerful role within the family is balanced against Otoe's (and Yumi's) own power in the broader, English-speaking community.

\section{3. "No, Japanese"}

In the next excerpt, Mami instructs her daughters in the proper methods of skewering meat in order to cook it. Two activities, cooking and teaching, are both associated with the role of Mother, and thus are enacted through the medium of Japanese. However, Mami's uncertainty, visible through the use of interrogative hedges (nan tte iu "what should I say"; dokka "somewhere") and softeners, weakens her position here. While Otoe continues to use Japanese, maintaining the established frame, Yumi breaks into English. I think they went diagonally when they pierced it. Yumi does not receive instruction from Mami, but offers it, inverting the Teacher/Student relationship. At the same time, the switch from Japanese to English may locate this exchange outside the frame of the family hierarchy. As mentioned in section 2.2, English is associated with powerful positions outside of the family.

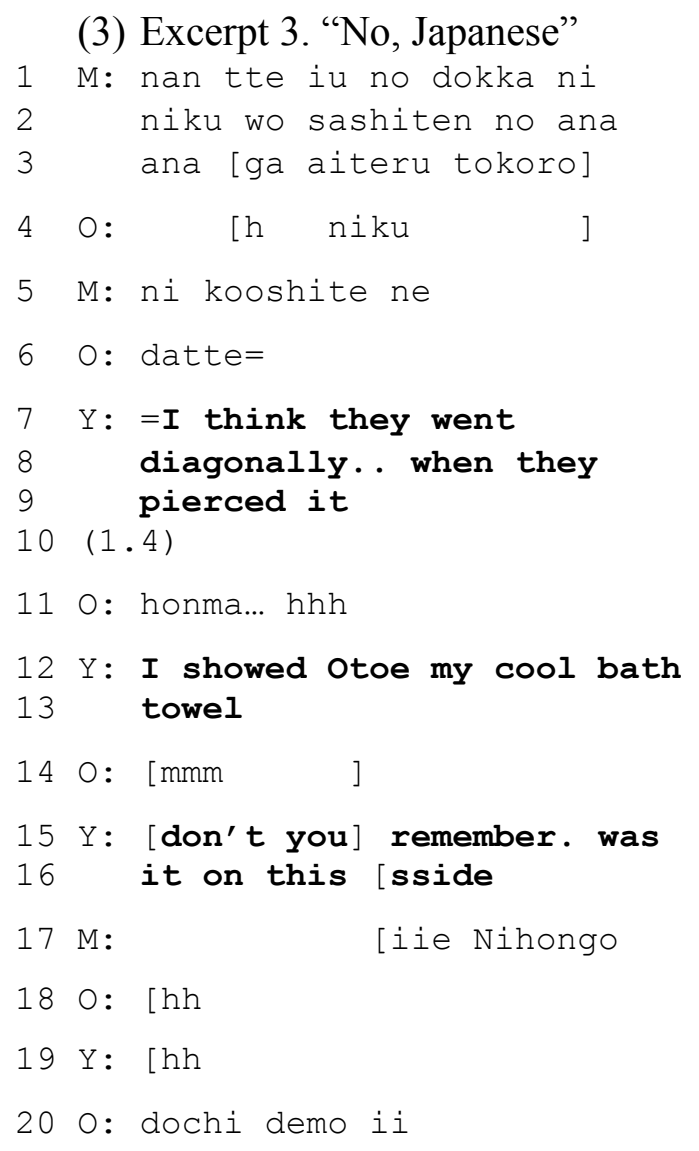

What- where should I skewer the meat, that- through that hole, where the hole is open

$h$ meat

this way.

well

I think they went diagonally, when they pierced it.

really ... hhh

I showed Otoe my cool bath towel.

$\mathrm{mmm}$

Don't you remember? Was it on this side

No, Japanese

Either is OK. 
It just came out.

Yumi's English contribution (lines 7-9) is greeted by a long silence. Otoe is the first to break this silence, speaking a single word' of Japanese at low volume. Thus, Otoe has not followed Yumi out of the established frame. She does not take up Yumi's language choice, nor does she continue the discussion.

Following this problematic exchange, Yumi changes the subject. Her remark, $I$ showed Otoe my cool bath towel, is addressed to Mami in English. While the use of English marks a break from Mami's lesson, it continues the language choice made in the problematic section. At line 17 Mami explicitly addresses Yumi's utterances as delivered in the wrong language: iie, Nihongo "No, Japanese." By censuring talk, particularly the form of talk, Mami presents herself as Authority, attempting to reestablish herself at the top of the hierarchy. Rather than acquiescing to the attempted censure, however, the daughters take up Mami's utterance as the opening of a negotiation. Yumi's plea, Katte ni deta no "It just came out," may be taken as an appeal addressed to an Authority. However, Otoe does not recognize Mami as Authority, instead placing herself in that role and judging Yumi's contribution as in bounds. Dochi demo ii "Either way is OK."

\section{4. "Excuse my pleasure"}

Otoe often places herself in the role of Authority, as in the preceding exchange. This strategy puts her in a locally strong position relative to those being judged. This can test Mami's dominant position, as in excerpt three, and therefore challenge the family hierarchy. More often, though, Otoe serves as Authority in disputes among her siblings, as in the following passage. This is a proper role within the family frame, given Otoe's role as older sibling.

(4) Excerpt 4. "Excuse my pleasure"

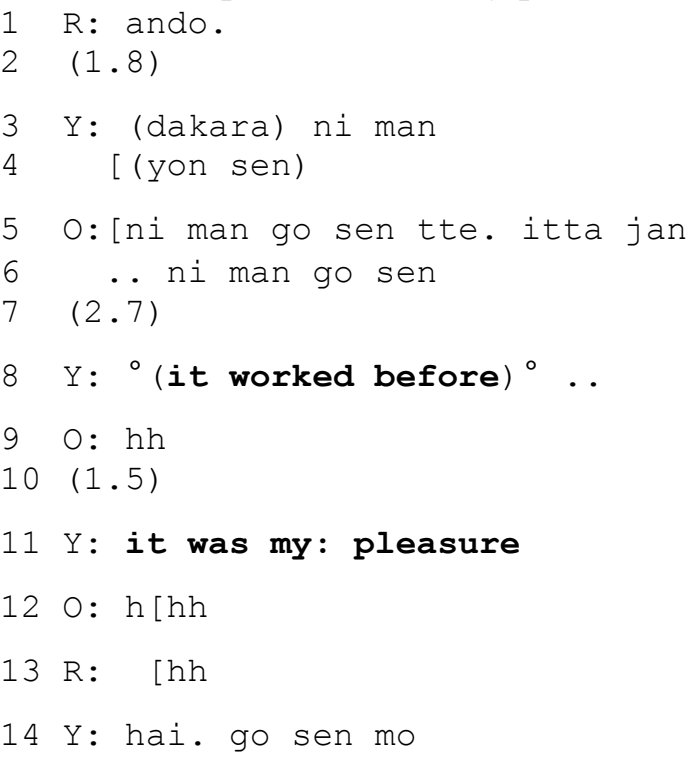

and

(So,) twenty (four) thousand

It said twenty five thousand. It's twenty-five thousand.

It worked before.

((laugh))

It was my pleasure.

((laugh))

((laugh))

Right. five thousand more

${ }^{7}$ Otoe's honma "really" is perhaps strategically ambiguous. It could be taken as either agreement with, or questioning of Yumi's assertion. 
15 [ (inaudible)

16 : [ no no no no no

$17 \mathrm{R}:[\mathrm{hhh}$

18 0: ekusukyu:z mai: purezha:

19 R: hh ((claps hands))

20 0: hai

210 : soo soo

22 R: a- arf arf

23 o: aho. aho. no, no, no

((laugh))

"Excuse my pleasure"

((laugh))

yeah

right, right

a- arf arf

idiot. idiot

Here, Otoe, Yumi, and Ryu are playing a board game. It seems that Yumi is trying to cheat, offering to pay twenty-four thousand dollars (lines 3-4), when she owes twentyfive thousand. Otoe corrects her, and Yumi gathers the correct sum. At line eight, Yumi switches from Japanese to English, offering a sotto voce aside in which she reveals that she may be in the habit of misrepresenting the sums she owes: It worked before. This switch from game play to evaluation is a change in footing (Goffman, 1979), and thus an appropriate occasion for code switching. However, when Yumi returns to game play (line 11), her continued use of English is seen as a problem.

At line 11, Yumi adopts a very affected tone of voice as she hands over the money she owes. She speaks in a lower pitch than usual, and lengthens her words, perhaps attempting to play some sort of character. Moreover, she speaks English, and uses a somewhat stilted expression. Her odd performance is greeted by laughter from Otoe, with Ryu joining in immediately after (lines 12-13). Yumi attempts to escape this laughter by returning straight away to the game. Otoe will not allow Yumi to elude judgment, however. At line eighteen, she parodies Yumi's odd expression. Rather than simply repeating what Yumi said, Otoe reworks the expression slightly, rendering it utterly nonsensical. Excuse my pleasure. Moreover, although Otoe, like Yumi, uses a low pitch, she delivers the expression with an exaggerated Japanese accent. Neither Yumi nor Otoe normally have a Japanese accent when speaking English, and Yumi's previous English utterance had no such accent. Otoe seems to draw on discourses from the broader US social setting that associate non-standard, especially foreign accented English with foolishness and social ineptitude.

In this interaction, Otoe is able to present herself as the linguistic authority. She treats some code switching as appropriate and acceptable, as when Yumi (line 8) or Ryu (line 1) evaluate or comment on the game. Similarly, Otoe herself sometimes uses code switching to show such changes in stance or topic. This is similar to the use of code switching for realignment or control that Zentella (1997) describes among SpanishEnglish bilinguals. However, not all code choices are treated as legitimate. Otoe judges her siblings' language behavior, censuring inappropriate conduct. By selectively ratifying certain actions, but censuring others, Otoe helps to teach Yumi and Ryu what range of behavior is considered appropriate within the family. At the same time, though, Otoe claims for herself the same powerful position that Mami occupies in other interactions. As with all such practice, the effects of the interaction have a range of consequences for each participant. 


\section{5. "Pay day"}

As these excerpts illustrate, the members of Mami's family conduct themselves within a family hierarchy. Their behavior toward one another is partially structured according to locally relevant norms of interaction, which in turn are situated within broader social structures. As Mother, Mami is entitled to judge the behavior of her children, and to direct their behavior. At the same time, she is obliged to offer them instruction and care. Conversely, the children are not expected to offer Mami instruction or judgment. That is not to say that the children do not offer these things, but that when such events occur, they are marked as out of the ordinary. Silences and code switching provide particularly visible marks of these shifts.

Mami sits atop a family hierarchy. The hierarchy is further ranked by age divisions, with older sister Otoe holding more power than either of her siblings. This should not be taken to mean, however, that chronological age is by itself constitutive of position. Rather, the hierarchy is created through social practices, each of which is subject to ratification by fellow actors. As excerpt five shows, even the youngest member of the family can claim the privileged position by refusing to ratify invalid acts.

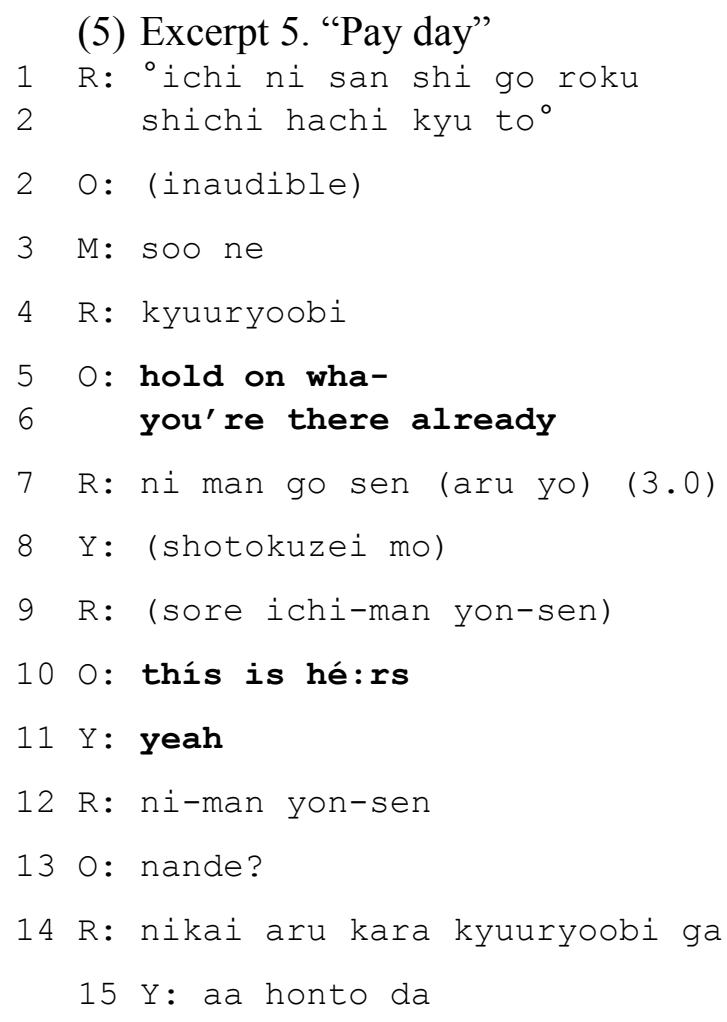

One two three four five six seven eight nine ten

( )

That's right.

Pay day.

\section{Hold on wha-} you're there already.

(there are) twenty five thousand.

(and income tax.)

That's fourteen thousand.

This is hers.

yeah

Twenty four thousand.

Why?

Because there are two pay days.

Oh, that's right.

Excerpt five occurs just prior to excerpt four (section 2.4). Recall that while Yumi's use of English within game play was ruled out of bounds, switching to English as a change in footing received no censure. Again in excerpt five, English is used outside of actual game play. At line five, Otoe challenges Ryu, who is demanding to be paid, according to the rules of the game. Otoe makes this challenge in English, marking her role as Authority. 
Ryu does not respond to this challenge, however. At line seven, he reinstates his demand by naming - in Japanese - the figure he is to be paid. Yumi follows Ryu, both in code choice and by addressing herself to the game, not Otoe's criticism of Ryu. Otoe's next challenge (line 10) is made more forcefully, again in English. This time, Yumi follows Otoe, using the English yeah to voice agreement. However, Ryu refuses to recognize Otoe's censure, continuing to play the game and to speak Japanese. By not ratifying Otoe's stance as Authority, Ryu has effectively denied her that stance. This behavior, with Yumi's eventual ratification (line 15), allows Ryu to win the exchange, and illustrates the interactional nature of these stances.

\section{Conclusions}

The family hierarchy alluded to here is not a structure that exists independently of the actions of its members. Rather, it is a web at once constraining the actions of family members, and woven by them (Geertz, 1973). The behaviors described here serve to create and to index social identities, to socialize fellow actors into locally relevant patterns of 'common sense,' and to reproduce the hierarchy within which the behaviors themselves have power and significance. At the same time, broader discourses of language and of nation - both Japan and the US - are apparent. Large scale social orders such as nation-states and language 'communities' are experienced and largely constructed through face to face interactions with other individuals. ${ }^{8}$ At the same time, these structures exert power over individual actors.

This hierarchy of power and significance can be seen as a local symbolic market. The arrangement of subject positions with unequal access to approved forms of behavior, and unequal rights to exercise power is roughly isomorphic to the broader symbolic marketplace as described by Bourdieu (1977b; 1991) and others, as in a fractal shape. That the individuals examined here may be seen to reproduce the very marketplace in which they participate argues against Bourdieu's assertion that the state, particularly through the educational system, has sole control over the creation of symbolic markets. According to Bourdieu (1977b:652), "The educational system is a crucial object of struggle because it has a monopoly over the production of the mass of producers and consumers, and hence over the reproduction of the market on which the value of linguistic competence depends." Although the educational system may be among the most common and powerful of institutions within many cultures, it does not have a monopoly over social actors. ${ }^{9}$ At the same time, these actions conform to broad social norms experienced outside of the family as well. Each individual performs within a range of institutions and frames, with a number of fellow actors. Each of these interactions can have a constitutive effect on not only the identity of the individuals, but also on market formation, distinction, and symbolic domination.

The traditional, 'macroeconomic' view of political economy focuses on societies, regions, and nations. A microeconomic approach to symbolic domination takes seriously Suleiman's reminder that institutions such as the nation-state, as a conflation of the political state with a 'culture,' are comprised of individual actors. "[Collective] identities

${ }^{8}$ Though, of course, one should not forget the role of media texts, consumer goods, etc. in constructing such imagined communities (Anderson, 1983).

${ }^{9}$ For fuller critiques, see Woolard (1985), Gal (1989), Briggs and Bauman (1992), and Hill (1993), inter alia. 
are experienced at the personal level[;] it is the individual who experiences these identities and gives them meaning in his or her social and cultural setting" (Suleiman, 2003:5). Political micro-economy takes as its focus the daily interactions of individuals as both acts of identity and steps in the constitution of symbolic markets and individual habitus.

Face-to-face conversation takes place within a system of symbolic power relations. In this, political micro-economy echoes Bourdieu (1977a:650). "To give an account of discourse, we need to know the conditions governing the constitution of the group within which it functions: the science of discourse must take into account not only the symbolic power relations within the group concerned... but also the laws of production of the group itself." Furthermore, account must be taken not only of class positions, but also of a range of identity positions. Social positions such as age (Eckert, 2003), gender (Eckert and McConnell-Ginet, 1992; Ortner, 1996), ethnicity (Said, 1978; Suleiman, 2003) etc. are constructed by individuals acting within an encompassing structure. As Eckert and McConnell-Ginet (1992:462) put it, "It is the mutual engagement of human agents in a wide range of activities that creates, sustains, challenges, and sometimes changes society and its institutions." This study has been an attempt to show how micro-level interactions both reflect social schemas and help to reproduce them. Future work should take a gradually more encompassing view of social interaction among families, congregations, neighborhoods, cities, and even nations. Such an expanding focus is necessary to trace the borders of particular symbolic economies.

\section{References}

Althusser, Louis, 1972. Lenin and philosophy, and other essays. Monthly Review Press, New York,.

Anderson, Benedict, 1983. Imagined communities: reflections on the origin and spread of nationalism. Verso, London.

Austin, J. L., 1962. How to do things with words. Clarendon Press, Oxford,

Bateson, Gregory, 1936. Naven, a survey of the problems suggested by a composite picture of the culture of a New Guinea tribe drawn from three points of view. The University Press, Cambridge.

Bourdieu, Pierre, 1977a. The economics of linguistic exchanges. Social science information 16, 645-668.

Bourdieu, Pierre, 1977b. Outline of a theory of practice. Cambridge University Press, Cambridge and New York.

Bourdieu, Pierre, 1982. Ce que parler veut dire: l'économie des échanges linguistiques. Fayard, Paris.

Bourdieu, Pierre, 1991. Language and symbolic power. Cambridge University Press, Cambridge.

Briggs, Charles L. and Bauman, Richard, 1992. Genre, intertextuality, and social power. Journal of Linguistic Anthropology 2, 131-172.

Bucholtz, Mary and Hall, Kira, 2004. Language and identity. In: Duranti, A. (Ed.), A companion to linguistic anthropology, Basil Blackwell, Oxford, pp. 268-294.

Cashman, Holly, 2001. Doing being bilingual: language maintenance, language shift, and conversational codeswitching in southwest Detroit. University of Michigan, Ann Arbor. 
Eckert, Penelope, 2003. Language and adolescent peer groups. Journal of Language and Social Psychology 22, 112-118.

Eckert, Penelope and McConnell-Ginet, Sally, 1992. Think practically and look locally: language and gender as community-based practice. Annual Review of Anthropology 21, 461-490.

Friedrich, Paul, 1989. Language, ideology, and political economy. American Anthropologist 91, 295-312.

Gal, Susan, 1989. Language and political economy. Annual Review of Anthropology 18, 345-367.

Geertz, Clifford, 1973. Thick description: toward an interpretive theory of culture. In: (Ed.), The interpretation of cultures, Basic Books, New York, pp. 309-323.

Goffman, Erving, 1979. Footing. Semiotica 25, 1-29.

Heritage, John, 1984. Garfinkel and ethnomethodology. Polity Press, Cambridge [Cambridgeshire]; New York, N.Y.

Herzfeld, Michael, 2001. Anthropology: theoretical practice in culture and society. Blackwell, Malden, MA.

Hill, Jane, 1993. Structure and practice in language shift. In: Hyltenstam, K. and Viberg, A. (Ed.), Progression and regression in language: sociocultural, neuropsychological, and linguistic perspectives, Cambridge University Press, Cambridge, pp. 68-93.

Irvine, Judith, 1989. When talk isn't cheap: language and political economy. American Ethnologist 16, 248-267.

Irvine, Judith and Gal, Susan, 2000. Language ideology and linguistic differentiation. In: Kroskrity, P. (Ed.), Regimes of language: ideologies, polities, and identities, School of American Research, Santa Fe, pp. 35-83.

Javanaud, Pierre, 1987. What is language all about? Journal of Pragmatics 11, 799-815. Jefferson, Gail, 1984. Notes on a systematic deployment of acknowledgement tokens "yeah" and "mm hm". Papers in Linguistics 17, 197-216.

Langager, Mark, 2001. Sojourning with children: the Japanese expatriate educational experience. Harvard, Cambridge, MA.

Lo, Adrienne, 1999. Codeswitching, speech community membership, and the construction of ethnic identity. Journal of Sociolinguistics 3/4, 461-479.

Mey, Jacob, 2006. Pragmatics: overview. In: Brown, E. K. (Ed.), Encyclopedia of language and linguistics, Elsevier, Amsterdam and London, pp. 51-62.

Ochs, Elinor, 1993. Constructing social identity: a language socialization perspective. Research on Language and Social Interaction 26, 287-306.

Ortner, Sherry, 1989. High religion: a cultural and political history of sherpa Buddhism. Princeton University Press, Princeton.

Ortner, Sherry, 1996. Making gender: the politics and erotics of culture. Beacon Press, Boston.

Said, Edward, 1978. Orientalism. Pantheon Books, New York.

Sapir, Edward, 1995. The unconscious patterning of behavior in society. In: Blount, B. (Ed.), Language, culture, and society, Waveland Press, Prospect Heights, IL, pp. 64-84. 
Silverstein, Michael, 1995. Shifters, linguistic categories and cultural description. In: Blount, B. (Ed.), Language, culture, and society, Waveland Press, Prospect Hills, IL, pp. 187-221.

Smith, Adam, 1993. An inquiry into the nature and causes of the wealth of nations. Oxford University Press, Oxford.

Social Science Data Analysis Network, 2002. CensusScope. http://www.censusscope.org/index.html

Suleiman, Yasir, 2003. The Arabic language and national identity. Georgetown University Press, Washington.

Takayasu, Hideki, Takayasu, Misako, Okazaki, Mitsuhiro and Shimizu, Tokiko, 2000. Fractal properties in economics. In: Novak, M. (Ed.), Paradigms of complexity: fractals and structures in the sciences, World scientific publishing company, Singapore, pp. 243-258.

Woolard, Katherine, 1985. Language variation and cultural hegemony. American Ethnologist 12, 738-748.

Woolard, Katherine, 1989. Double talk: bilingualism and the politics of ethnicity in Catalonia. Stanford University Press, Stanford.

Zentella, Ana Celia, 1997. Growing up bilingual. Blackwell, Malden, MA. 